\title{
The Effects of Integrated Technology-based Approach and Peer Coaching in Teaching Geometry: A Closer Look at Teachers' TPACK and Students' Understanding
}

\author{
Lilla Adulyasas ${ }^{1}$, Nuchanart Temdee ${ }^{2}$ \\ ${ }^{a}$ Faculty of Science Technology and Agriculture, Yala Rajabhat University, Thailand \\ ${ }^{\mathrm{b}}$ Faculty of Science Technology and Agriculture, Yala Rajabhat University, Thailand
}

Article History: Received: 10 November 2020; Revised: 12 January 2021; Accepted: 27 January 2021; Published online: 5 April 2021

\begin{abstract}
The technological pedagogical content knowledge (TPACK) framework has been used widely in mathematics education in various contexts. However, teachers may confront with difficulties while applying technology in classroom teaching and need to cooperate with others in designing and implementing technology-based lesson for an effective teaching and learning. Peer coaching is one of the cooperating process which supports and encourages teachers in generating ideas for improving classroom teaching. This research aimed to study on the effects of integrated technology-based approach and peer coaching on teachers' TPACK and students' understanding in learning geometry of secondary level. The participants were three in-service teachers and one pre-service teacher who had taught geometry in seventh grade in a school in Yala, Thailand and the samples were thirty-two seventh grade students in the school. The researcher employed questionnaire and open-ended questions for assessing teachers' TPACK, while geometric achievement test was employed to examine students' understanding before and after learning with the integrated approach. Data were collected under the peer coaching process for assessing teachers' TPACK during designing and implementing the integrated approach in teaching geometry. Pre-test and post-test were given to the students before and after learning respectively. Descriptive statistics was used to describe teacher's TPACK while a developmental model for TPACK was used as a lens for examining the teacher's TPACK. In addition, paired-samples $t$ test and one-sample $t$ test were used to determine students' understanding in geometry. Findings revealed that the designing and implementing of the integrated approach for teaching geometry under the peer coaching process enabled teachers to enhance their TPACK and the students to improve their understanding in learning geometry. The implications of this research are provided along with suggestions.
\end{abstract}

Keywords: Technology-based approach, Peer coaching, TPACK, Geometry, Secondary level

\section{INTRODUCTION}

Geometry, one of the focal topics in mathematics is a fundamental skill (National Council of Teachers of Mathematics, 2000) in facilitating students' problem-solving skills across various topics in teaching of mathematics and real-life experience through representation (Clements, 2003). Teaching Euclidean geometry is vital in both primary and secondary levels of the school system. Primary level students are taught skills such as analysing and understanding features and properties of different geometric shapes, constructing arguments of mathematical relationships in geometry as well as applying visualisation, spatial reasoning and geometric modelling (National Council of Teachers of Mathematics, 2000) while secondary level students learn various skills in practicing, drawing, constructing, investigating, observing, conjecturing about geometric properties, proving, analysing, and justifying with conclusions and reasonings (Serkoak, 1996). Essentially, teaching students to understand these skills provide them with a solid foundation to solve problems, appreciate mathematics and further support them in their pursuit of higher education.

Teaching and learning geometry is widely emphasised in Thailand secondary schools, nevertheless it remains a pedagogical challenge to teachers and students. Conventional elementary and middle school geometry curricula, which is known to underscore the importance of teaching students a structured list of definitions and properties of shapes seems misleading. Battista's (2002) study proposed that students should develop meaningful geometric concepts and analyse spatial problems and situations through robust reasoning instead of memorizing and regurgitating definitions and properties. Students could be discouraged due to the lack of understanding in learning geometry and ultimately lead to their poor subject performance. Academic result in Trends in International Mathematics and Science Study (TIMSS) 2015 reported evidence of learning and teaching geometry failure in Thailand. Thai students' below-standard results with a mean score of 429 in comparison to the 500-mark global benchmark revealed their overall failure, which consequently caused Thailand to rank at $30^{\text {th }}$ from 39 participating countries in 2015 (Mullis, Martin, Foy, \& Hooper, 2015).

Echoing the critical scenario of geometry pedagogy in Thailand and aligning with NCTM's Principles and Standards for School Mathematics, scholars suggested the use of technology-integrated teaching and learning approaches through interactive geometry software to enhance students' learning (National Council of Teachers of 
Mathematics, 2000). To date, it has been accepted that the use of technology with technology-based approach well supports and enhances learners' learning of geometry in $21^{\text {st }}$ century. Currently, there is a wide range of openmarket commercial teaching and learning mathematics and geometry software such as Geometer's Sketchpad, Derive, Cabri, Matlab, and Autograph which have been used in schools and universities worldwide (Saha, Ayub, \& Tarmizi, 2010). GeoGebra program and Tinkercad program are alternative freeware for learning geometry. Moreover, mobile or tablet application are prevalent technologies in this digital era.

Acknowledging the prevalence of how teaching and learning geometry has shifted towards a technologydriven direction, thus managing effective teaching of geometry supported by technology integration is essential for teachers. Mishra and Koehler (2006) developed the theoretical framework of Technological Pedagogical Content Knowledge (TPACK) which was defined as the teacher's knowledge in teaching a particular content assisted with technology. This premise includes three aspects; (i) Technological Knowledge, (ii) Pedagogical Knowledge, and (iii) Content Knowledge, which are typically implemented for promoting effective teaching and learning through technology integration. TPACK is described as a foundation of success in teaching and learning which is relevant to the use of technology whereby it encourages knowledge and understanding of concepts by organizing and conveying creative teaching and learning in diverse contents (Mishra \& Koehler, 2006; Koehler \& Mishra, 2009).

It is imperative for teachers to have knowledge and understanding of integrating the three aspects in TPACK. In addition, Niess et al. (2009) proposed a Developmental Model for TPACK, in which mathematics teachers should develop their knowledge in integrating technology with pedagogy and teaching content through the five hierarchical steps starting from Pedagogical Content Knowledge or PCK, the theoretical framework of Shulman (1986). When technology is applied in teaching and learning, teachers integrate technology into pedagogy and teaching content from Level 1 (Recognizing), Level 2 (Accepting), Level 3 (Adapting), Level 4 (Exploring) to Level 5 (Advancing). Level 5 serves as an indicator for the success of integrating technology with pedagogy and teaching content or the TPACK level of the teacher as shown in Figure 1.

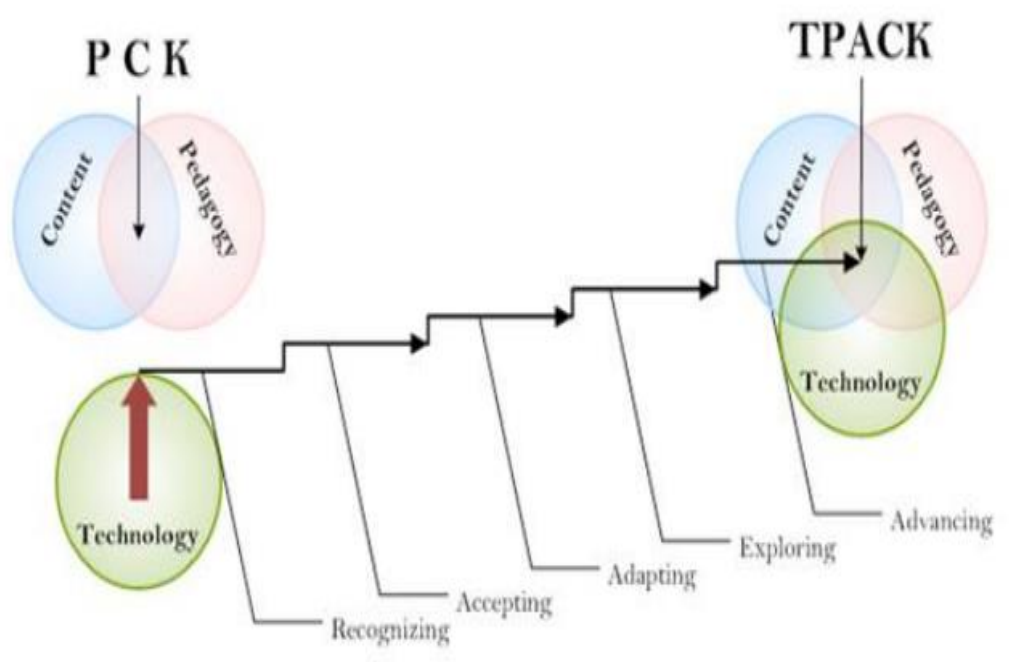

Figure 1. A developmental model for TPACK (Niess et al., 2009)

In this study, the researchers discovered three types of technologies which could facilitate and improve students' geometry learning. The first is GeoGebra program, a program for Mathematics specifically for learning geometry and algebra (Hohenwarter \& Fuchs, 2004) was designed to combine features of dynamic geometry software (e.g., Cabri Geometry, Geometer's Sketchpad). Currently, GeoGebra plays an effective role in teaching and learning in geometry, whereby students can use it to construct geometric objects, observe how these objects change when moving free points or applying Euclidian transformations, and discover conjectures. The second is a mobile or the tablet application for learning geometry designed by Adulyasas and Yathikul (2020). Adulyasas and Yathikul (2020) developed the tablet application to study its effectiveness on learning geometry, leading to positive results in increasing students' levels of geometric thinking due to the distinct transference of van Hiele's theory combined with phase-based learning, which ultimately supported the effective learning geometry on the tablet application. The third is Tinkercad program, a web-based online tool. Using Tinkercad program, students can easily upgrade their skills and effectively use the programming knowledge to understand both theory and practice within geometric concepts because it is an easy-to-use application for 3D design. Through the simulated Tinkercad program, students can also easily identify the required logical development and automatically prompt their thinking to resolve a specific set of problems or goals. As a web-based online tool, Tinkercad program enables users to easily monitor and accommodate any required result-oriented performance anytime and anywhere through the use of a mobile or personal computer (Mohapatra, Mohapatra, Joshi, \& Zagade, 2020). 
Despite the availability of hardware and software within the landscape of technology-rich secondary schools and the importance of integrating technology in teaching and learning, teachers rarely use computers in their teaching due to their ingrained believe in their existing pedagogy, time constraint and their preference towards particular text resources. Moreover, some teachers had cultivated a narrow viewpoint about the potential of computer in teaching and learning from their established perspectives of teacher-centred and content-focus pedagogy (Norton, McRobbie, \& Cooper, 2000; Pelgrum, 2001; Shamburg, 2004). A factor that influences mathematics teachers' TPACK is their individual specialization of teaching expertise which directly restrain the teachers' pedagogical capacity due to their deficient knowledge about technology integration in their teaching (Adulyasas, 2017). The researcher proposes colleagues and experts' help on teachers' professional development using technology integration for an effective teaching as studies have shown successful management in learning via various stakeholders' collaboration.

Today, coaching is considered as one of the effective and widely used approach in building professional development. In teaching and learning, teacher's colleagues and experts can be engaged to improve the process for effectiveness in students' learning. A community of peers plays an important role in providing support and serving as a resource for idea-generation and critiques (Sykes, 1996). Along the vein of community-oriented coaching, the concept of peer coaching has been widely investigated ( $\mathrm{Lu}, 2010)$. It generally means two or more professional colleagues working together to share ideas, teach one another, conduct classroom investigation, reflect on current practices, and build new skills or solve problems in the workplace (Arslan \& Ilin, 2013). Peer coaching typically consists of four key factors: academic support, technical support, emotional support, and reflective support (Zhang, Liu, \& Wang, 2017) in which teachers can convene for mutual support through sharing their resources, solving problems, developing working strategies, and improving their performances. Therefore, peer coaching can be a powerful model for teacher education programs (Rice, 2012).

With the aforementioned explanation, the researchers crystallized an idea to take the process of peer coaching into account for developing teachers' TPACK in order to promote an effective technology-based teaching and learning of geometry which is ultimately able to bring a positive effect on students' learning outcome. Therefore, the researchers intended to investigate the effects of integrated technology-based approach and peer coaching on teachers' development of TPACK and students' understanding in geometry. An initial step undertaken in conducting this research started with developing technology-based lesson plans for teaching geometry to seventh-grade students under the process of peer coaching. This research was carried out with three main aims, that is, (i) to examine the efficiency of the developed technology-based lesson plans using a criterion of E1/E2 with an equivalent to 80/80, (ii) to figure out the effects of the integrated technology-based approach on the teachers' development of TPACK and (iii) to determine its effects on seventh-grade students' understanding in learning geometry. With the research aims driven in the present study, it is hoped to constitute a development of effective teaching and efficient learning in geometry for the learners.

\section{Materials and Methods}

\subsection{Research Design}

This research was conducted with mixed-method research design. Qualitative approach was applied to find the effects of the integrated technology-based approach and peer coaching on the teachers' development of TPACK. For quantitative approach, one group pre-test and post-test design was implemented to determine the students' understanding in learning geometry by using the developed lesson plans which relied on technologybased approach under the peer coaching process. To complete the research procedures, this research lasted for six months in the academic year of 2020.

\subsection{Participants and Samples}

The participants included three in-service teachers and one pre-service teacher teaching in a school in Yala Province, Thailand. The four teacher participants taught geometry to seventh-grade students in the school. The samples were 32 students of the school selected by purposive technique who voluntarily took part in the present study. They were seventh-grade students in one intact class under the pre-service teacher participant's teaching responsibilities.

\subsection{Instruments}

Three research instruments in this study consisted of:

(1) Integrated technology-based approach lesson plans under the peer coaching process for teaching and learning geometry for seventh-grade students which were verified by experts for content validity standard and showed its effectiveness based on a criterion of E1/E2 with an equivalent to 80/80.

(2) Questionnaire for assessing teachers' TPACK adopted from Schmid, Brianza, and Petko (2020) and open-ended questions for determining the teachers' development of TPACK which were checked by experts and were consolidated based on the feedback to make sure its content validity. 
(3) Geometric achievement test of 30 multiple-choice items with experts' endorsement of content validity which were tried out to determine its reliability, level of difficulty, and power of discrimination confirmed and guaranteed a good quality of measurement and its readiness for usage. The results of pilot study reported that the test showed 0.82 for the Cronbach's alpha of reliability, each item had a range between 0.26-0.59 for level of difficulty as well as obtained a range between $0.45-0.71$ for power of discrimination.

\subsection{Data Collection}

The data collection in the study took some steps. Firstly, Questionnaire for assessing teachers' TPACK was given to the teacher participants before they collaboratively worked and developed the technology-based approach lesson plans under the peer coaching process for an effective teaching geometry to seventh-grade students. Secondly, the developed lesson plans were tested and improved its effectiveness to fulfil the requirement. Then, the students were given geometric achievement pre-test. In the period of intervention, the researchers used the prepared open-ended questions to elicit the teacher participants' development of TPACK under the process of peer coaching which took place before, during, and after classroom teaching. Lastly, the students were asked to take geometric post-test after learning as well as questionnaire for assessing teachers' TPACK was given again to the teacher participants after teaching.

\subsection{Research Framework}

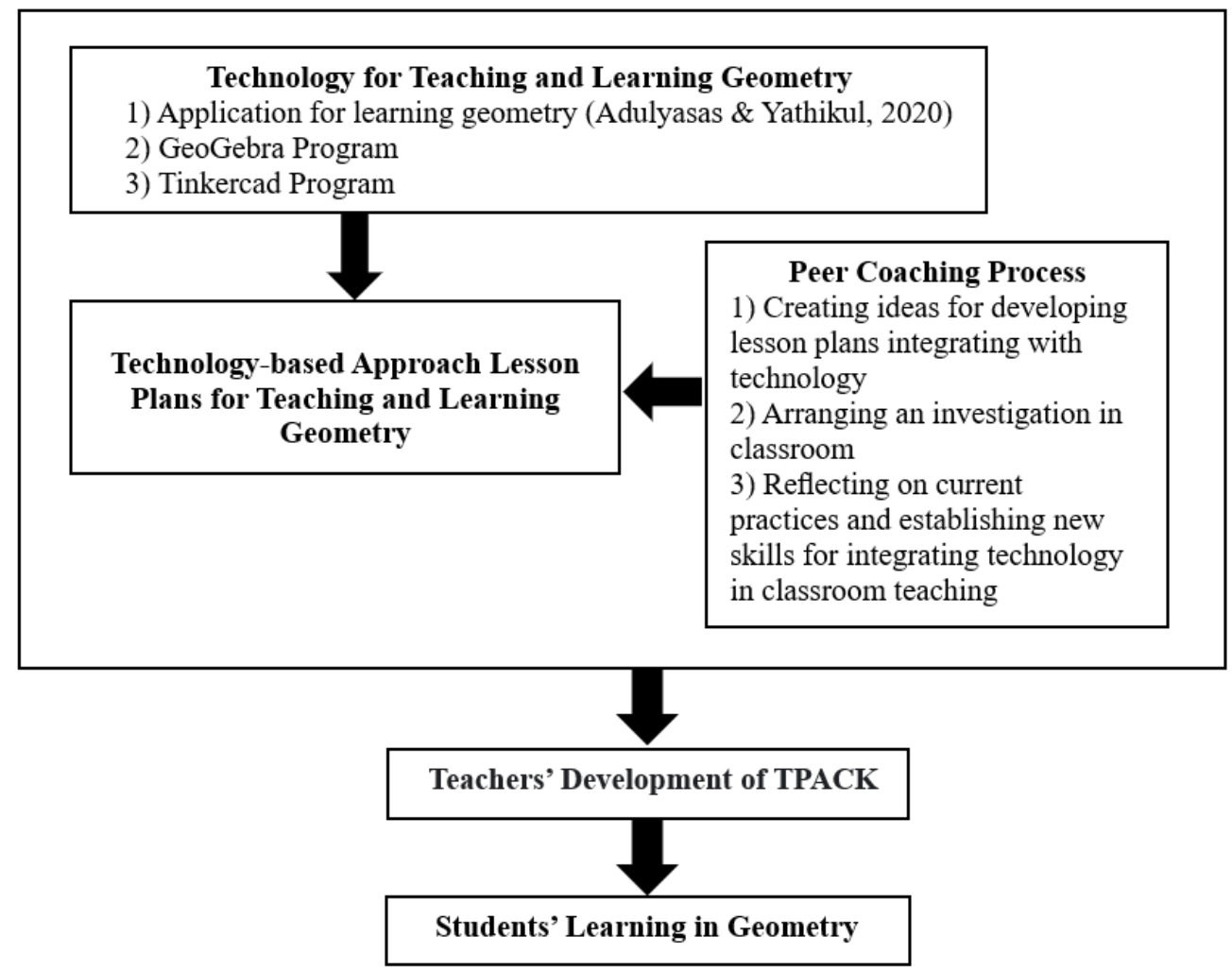

\subsection{Data Analysis}

Figure 2. Research framework

(1) The researchers used the criterion of E1/E2 with an equivalent to $80 / 80$ to identify the efficiency of the integrated technology-based approach lesson plans.

(2) Descriptive statistics was used to describe teachers' TPACK while content analysis was used to analyse qualitative data collecting from the teacher participants' development of TPACK by adopting a Developmental Model for TPACK (Niess et al., 2009) as a lens to identify their levels of TPACK. The five different levels of the TPACK as defined by Niess et al. (2009) are as follows:

Level 1: Recognizing (knowledge), where teachers are able to use the technology and recognize the alignment of the technology with mathematics content yet do not integrate the technology in teaching and learning of mathematics.

Level 2: Accepting (persuasion), where teachers form a favourable or unfavourable attitude toward teaching and learning mathematics with an appropriate technology.

Level 3: Adapting (decision), where teachers engage in activities that lead to a choice to adopt or reject teaching and learning mathematics with an appropriate technology. 
Level 4: Exploring (implementation), where teachers actively integrate teaching and learning of mathematics with an appropriate technology.

Level 5: Advancing (confirmation), where teachers evaluate the results of the decision to integrate teaching and learning mathematics with an appropriate technology.

(3) Paired-samples $t$ test was used to compare the students' mean scores before and after learning geometry with the integrated technology-based approach to determine whether post-test mean score shows a statistically significant difference than that pre-test mean score or not while one-sample $t$ test was used to compare the students' achievement with standard score of $60 \%$ to see if post-test mean score shows a statistically significant lower or greater than the target criterion.

\section{Results}

\subsection{The Integrated Technology-based Approach Lesson Plans and Its Efficiency}

This research used the process of peer coaching for developing technology-based approach lesson plans for teaching geometry to seventh-grade students. Three selected types of technology integration in the present study included the Application for learning geometry which was designed and used in the study of Adulyasas and Yathikul (2020), GeoGebra program, and Tinkercad program. Examples of the use of the three types of technology integration in the lesson plans and its efficiency are as follows.

(1) Examples of the use of the Application for learning geometry of Adulyasas and Yathikul's (2020) research in conducting a number of different activities in classroom teaching and learning is provided as follows.

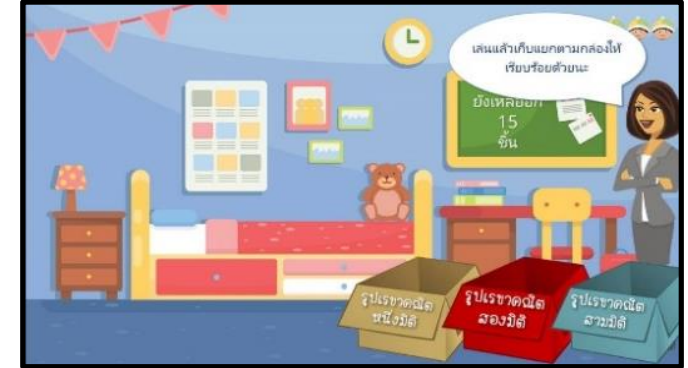

Figure 3. Practice for classifying

different dimensions of geometric shapes

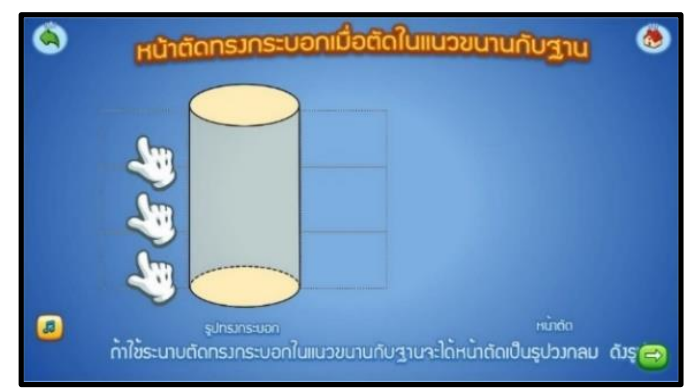

Figure 5. Learning cross-section of 3D geometric shapes

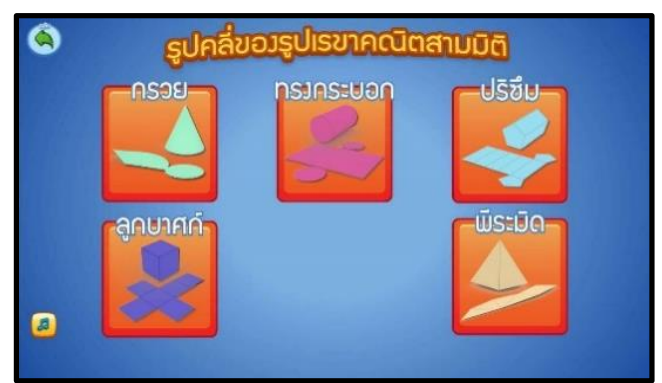

Figure 4. Learning nets of 3D

geometric shapes

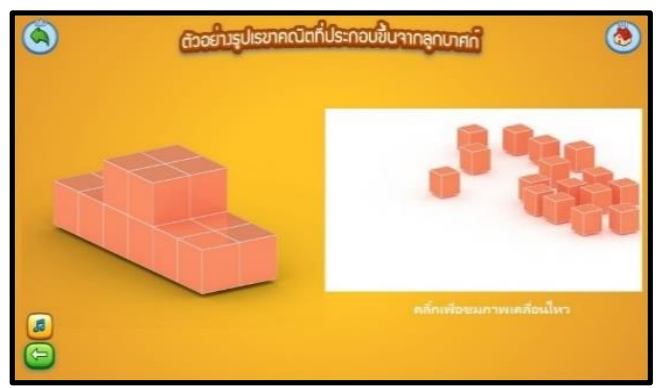

Figure 6. Learning 3D geometric shapes made up of cube

(2) Examples of classroom activities with the use of GeoGebra program are given as follows. 


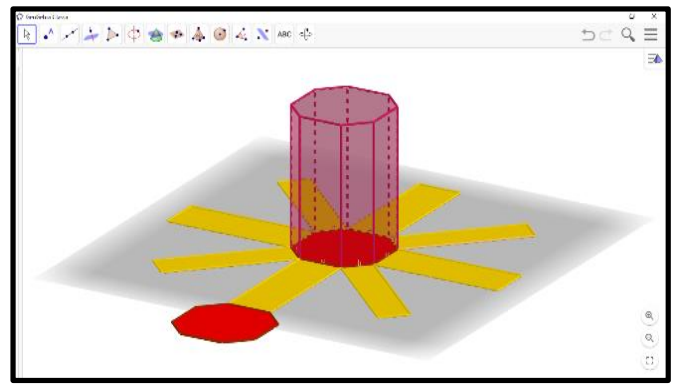

Figure 7. Learning nets of prism

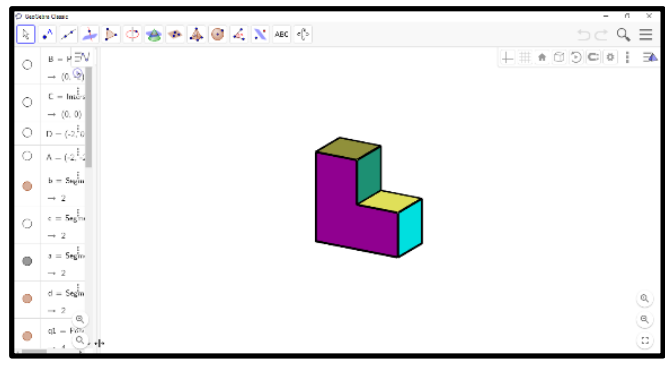

Figure 9. Learning of object visualization

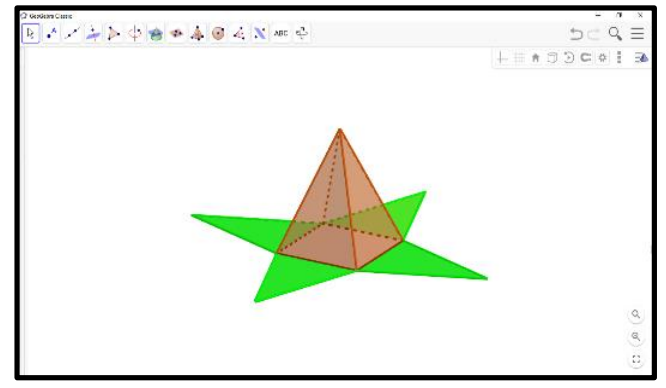

Figure 8. Learning nets of pyramid

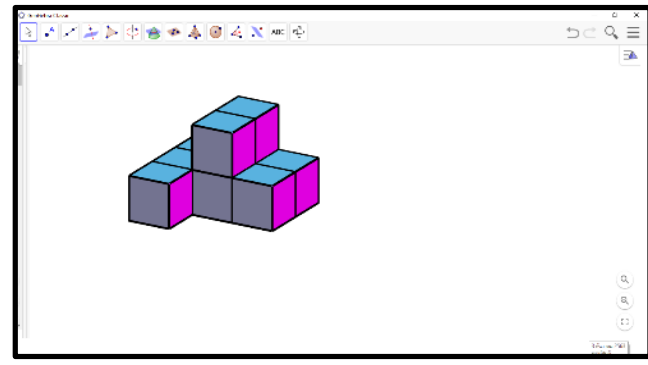

Figure 10. Learning of object

visualization from front view, side view, and top view

(3) Examples of how Tinkercad program used to convey the activities in classroom teaching are given as follows.

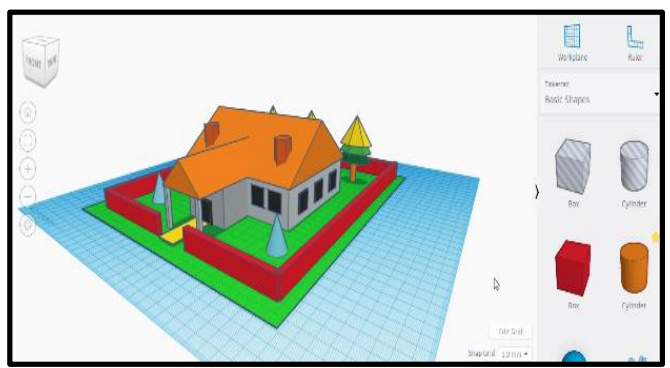

Figure 11. Learning the assembly of geometric shapes

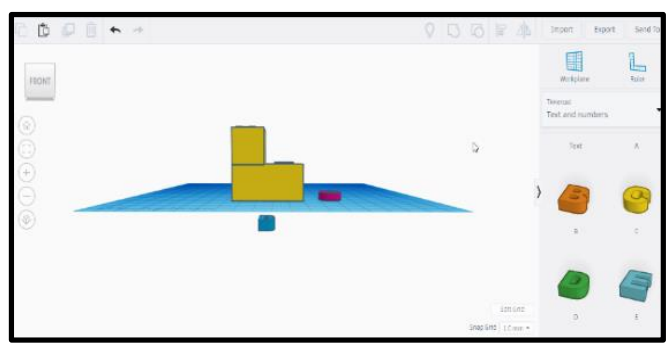

Figure 13. Learning of object visualization

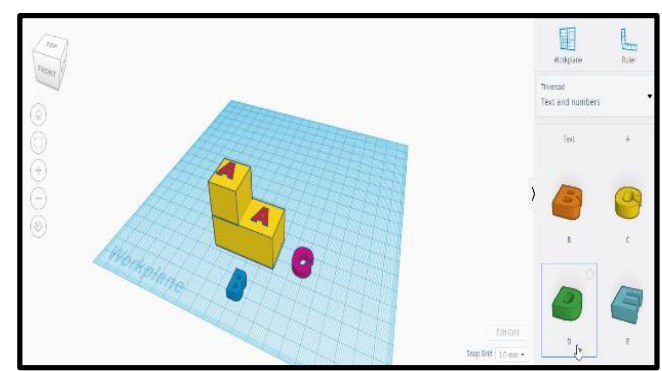

Figure 12. Learning of object

visualization from front view, side view, and top view

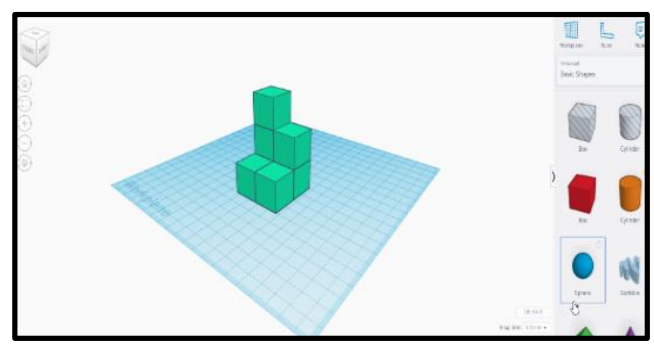

Figure 14. Learning of $3 D$ geometric shapes made up of cube 
(4) The efficiency of the developed integrated technology-based approach lesson plans

Table 1. Scores of five activities in different sub-contents, post-test scores, and the efficiency of lesson plans

\begin{tabular}{|c|c|c|c|c|c|c|c|}
\hline \multirow{4}{*}{$\begin{array}{l}\text { Stude } \\
\text { nt No. }\end{array}$} & Activit & Activit & Activit & Activit & Activity & \multirow{2}{*}{ Total } & \multirow{2}{*}{ Post-test } \\
\hline & y 1 & y 2 & y 3 & y 4 & 5 & & \\
\hline & $(20$ & $(20$ & $(20$ & $(20$ & $(20$ & $(100$ & $(30$ \\
\hline & marks) & marks) & marks) & marks) & marks) & marks) & marks) \\
\hline 1 & 17 & 19 & 19 & 18 & 19 & 92 & 29 \\
\hline 2 & 13 & 14 & 14 & 14 & 15 & 70 & 21 \\
\hline 3 & 12 & 13 & 13 & 14 & 15 & 67 & 21 \\
\hline 4 & 17 & 19 & 20 & 19 & 19 & 94 & 28 \\
\hline 5 & 14 & 15 & 15 & 15 & 16 & 75 & 22 \\
\hline 6 & 15 & 17 & 15 & 16 & 17 & 80 & 27 \\
\hline 7 & 16 & 18 & 16 & 17 & 18 & 85 & 26 \\
\hline 8 & 14 & 16 & 15 & 16 & 17 & 78 & 25 \\
\hline 9 & 16 & 18 & 19 & 18 & 19 & 90 & 24 \\
\hline Total & 134 & 149 & 146 & 147 & 155 & 731 & 223 \\
\hline Mean & 14.89 & 16.56 & 16.22 & 16.33 & 17.22 & 81.22 & 24.78 \\
\hline SD & 1.76 & 2.19 & 2.49 & 1.8 & 1.64 & 9.68 & 2.99 \\
\hline$\%$ & 74.44 & 82.78 & 81.11 & 81.67 & 86.11 & 81.22 & 82.59 \\
\hline
\end{tabular}

$\mathrm{E} 1 / \mathrm{E} 2=81.22 / 82.59$

From Table 1, five different lesson plans with different sub-contents in geometry were pilot-tested with nine students and the results revealed that the percentage of total mean score and post-test mean score were 81.22 and 82.59 respectively which fulfilled the required criterion of $80 / 80$. This can ensure that the developed integrated technology-based approach lesson plans have an efficiency and were effective for teaching geometry to seventh-grade students.

\subsection{Teachers' Development of TPACK}

3.2.1. Teachers' mean scores of TPACK

The researchers adopted Schmid et al.'s (2020) short assessment instrument for accessing the teacher participants' TPACK before and after teaching geometry to seventh-grade students with the integrated technology-based approach under the peer coaching process. Table 2 illustrates the four teacher participants' mean scores of TPACK in different subscales before and after the intervention.

Table 2. Teachers' mean scores of TPACK and TPACK subscales before and after the intervention

\begin{tabular}{|c|c|c|c|}
\hline & Before & & After \\
\hline TPACK and TPACK Subscales & $\begin{array}{l}\text { Me } \\
\text { an }\end{array}$ & SD & Me \\
\hline & & & \\
\hline I can adapt my teaching based upon what students & 4.00 & 0.82 & 4.50 \\
\hline
\end{tabular}




\begin{tabular}{|c|c|c|c|c|c|}
\hline PK2 & I can adapt my teaching style to different learners. & 4.00 & 0.82 & 4.25 & 0.50 \\
\hline PK3 & $\begin{array}{l}\text { I can use a wide range of teaching approaches in a } \\
\text { classroom setting. }\end{array}$ & 4.00 & 1.15 & 5.00 & 0.00 \\
\hline PK4 & I can assess student learning in multiple ways. & 3.25 & 0.50 & 4.25 & 0.50 \\
\hline \multicolumn{6}{|l|}{$\mathbf{C K}$} \\
\hline CK1 & $\begin{array}{l}\text { I have sufficient knowledge about my teaching } \\
\text { subject. }\end{array}$ & 4.25 & 0.50 & 4.50 & 0.58 \\
\hline CK2 & $\begin{array}{l}\text { I can use a subject-specific way of thinking in my } \\
\text { teaching subject. }\end{array}$ & 3.50 & 0.58 & 4.50 & 0.58 \\
\hline CK3 & $\begin{array}{l}\text { I know the basic theories and concepts of my } \\
\text { teaching subject. }\end{array}$ & 3.75 & 0.50 & 5.00 & 0.00 \\
\hline CK4 & $\begin{array}{l}\text { I know the history and development of important } \\
\text { theories in my teaching subject. }\end{array}$ & 3.25 & 0.96 & 4.00 & 0.00 \\
\hline \multicolumn{6}{|l|}{ TK } \\
\hline TK1 & I keep up with important new technologies. & 3.00 & 0.00 & 4.25 & 0.50 \\
\hline TK2 & I frequently play around with the technology. & 2.75 & 0.50 & 4.75 & 0.50 \\
\hline TK3 & I know about a lot of different technologies. & 2.75 & 0.50 & 4.75 & 0.50 \\
\hline TK4 & $\begin{array}{l}\text { I have the technical skills I need to use } \\
\text { technology. }\end{array}$ & 2.25 & 0.50 & 4.75 & 0.50 \\
\hline \multicolumn{6}{|l|}{ PCK } \\
\hline PCK1 & $\begin{array}{l}\text { I know how to select effective teaching } \\
\text { approaches to guide student thinking and learning in } \\
\text { my teaching subject. }\end{array}$ & 3.50 & 0.58 & 4.75 & 0.50 \\
\hline PCK2 & $\begin{array}{l}\text { I know how to develop appropriate tasks to } \\
\text { promote students complex thinking of my teaching } \\
\text { subject. }\end{array}$ & 3.25 & 0.50 & 4.50 & 0.58 \\
\hline PCK3 & $\begin{array}{l}\text { I know how to develop exercises with which } \\
\text { students can consolidate their knowledge of my } \\
\text { teaching subject. }\end{array}$ & 3.50 & 0.58 & 4.75 & 0.50 \\
\hline PCK4 & $\begin{array}{l}\text { I know how to evaluate students' performance in } \\
\text { my teaching subject. }\end{array}$ & \multicolumn{3}{|c|}{0.50} & 0.00 \\
\hline TPK & & & & & \\
\hline TPK1 & $\begin{array}{l}\text { I can choose technologies that enhance the } \\
\text { teaching approaches for a lesson. }\end{array}$ & 2.50 & 0.58 & 4.25 & 0.50 \\
\hline TPK2 & $\begin{array}{l}\text { I can choose technologies that enhance students' } \\
\text { learning for a lesson. }\end{array}$ & 3.00 & 0.00 & 4.25 & 0.50 \\
\hline TPK3 & I can adapt the use of the technologies that I am & 2.75 & 0.50 & 4.50 & 0.58 \\
\hline
\end{tabular}


learning about to different teaching activities.

$\begin{array}{llllllll}\text { TPK4 I am thinking critically about how to use } & 3.00 & 0.00 & 4.75 & 0.50\end{array}$ technology in my classroom.

\section{TCK}

TCK1 I know how technological developments have changed the field of my subject.

TCK2 I can explain which technologies have been used in research in my field.

TCK3 I know which new technologies are currently being developed in the field of my subject.

TCK4 I know how to use technologies to participate in scientific discourse in my field.

\section{TPACK}

TPAC I can use strategies that combine content

$\begin{array}{llll}2.75 & 0.50 & 5.00 & 0.00\end{array}$

$\mathrm{K}$ technologies, and teaching approaches that I learned about in my coursework in my classroom.

TPAC

I can choose technologies that enhance the content for a lesson.

TPAC I can select technologies to use in my classroom that enhance what I teach, how I teach, and what students learn. teaching subject, technologies, and teaching approaches

$\begin{array}{llll}3.11 & 0.5 & 4.49 & 0.28\end{array}$

\section{Average}

Table 2 reports that the teacher participants' mean scores of TPACK before and after teaching geometry with technology-based approach under the peer coaching process to seventh-grade students were $3.11(\mathrm{SD}=0.54)$ and 4.49 ( $\mathrm{SD}=0.28)$ which were in moderate level and high levels respectively. This indicated the development of teachers' TPACK. In addition, before teaching with the integrated technology-based approach, the lowest mean score among the teacher participants was in the item of 'I have the technical skills I need to use technology' (Mean=2.25, $\mathrm{SD}=0.50$ ) which was in the subscale of Technological Knowledge (TK). This meant that the teacher participants had a low technological knowledge. After teaching with the integrated technology-based approach, it was found that the teacher participants showed mean score of $5.00(\mathrm{SD}=0.00)$ for the item of 'I can use a wide range of teaching approaches in a classroom setting' in the subscale of Pedagogical Knowledge (PK), the item of 'I know the basic theories and concepts of my teaching subject' in the subscale of Content Knowledge (CK) as well as the item of 'I can use strategies that combine content, technologies, and teaching approaches that I learned about in my coursework in my classroom' in the subscale of Technological Pedagogical Content Knowledge (TPACK). The evidence indicated that the teacher participants developed their TPACK after going through the integrated technology-based approach under the peer coaching process.

Apart from that, the researchers used the open-ended questions to understand development of teachers' TPACK under the process of peer coaching before, during, and after teaching geometry to the students with the integrated technology-based approach. The questions in peer coaching were used to solicit the teacher participants (i) to identify problems which occurred in classroom teaching and specifying objectives in learning the subject 
matter, (ii) to analyse causes of the problems arisen in classroom teaching, how technology can support an effective learning in the subject matter, and which types of technology are appropriate for an effective learning, (iii) to design lesson plans integrating with suitable technologies for solving the problems and supporting learning goals as well as (iv) to understand how the appropriate technologies promote students' learning and how to improve teaching practices for the better learning outcome among students.

Prior to the teaching process, the four teacher participants collaborated to generate ideas for technology integration in lesson plans. Then, they observed teaching in classrooms which were taught by the pre-service teacher participants as a case study for classroom investigation. And, they participated in reflecting on their current teaching practices and creating new skills for integrating technology in their teaching. The data obtained at this stage were analysed by content analysis using a Developmental Model for TPACK adopted from Niess et al. (2009) for determining levels of the teacher participants' TPACK.

\subsubsection{Level of teachers' TPACK before teaching}

The analysis shows that two teacher participants had their TPACK at Level 1 because the teachers were able to employ the technology and realize the alignment of the technology for teaching mathematical contents; however, they failed to integrate the technology in their teaching practice in classroom. Additionally, another two teacher participants showed their TPACK at Level 2 since they were able to perceive a favourable or unfavourable attitude to teaching mathematics with an appropriate technology integration. The excerpts expressed their levels of TPACK are shown in Table 3.

Table 3. Teacher's excerpts and levels of TPACK before the intervention

Teac
hers
1 Today students had involved in the use of technologies. Yet, I did not
use it in my classroom consciously. The reason was that I did not have
chance for training and learning the use of appropriate technologies in
classroom teaching.
Technologies well facilitated the students' learning. However, I did
not think to apply in my classroom due to a large number of teaching
contents. Time allocation for teaching the contents was not even enough.
I knew and realised in the trend of teaching and learning in $21^{\text {st }}$
century which typically focused on the role of technologies in this era.
However, I believed that my teaching did not cause students' learning
any problems, and that was good enough for my students to understand
geometry.
I viewed the use of technologies advantageous in teaching but did not
have opportunities to use it for teaching. I intended to learn new
technologies before using in geometry class in next semester.

\section{Levels TPACK}

Level

Recognizing

Level

Recognizing

Level

Accepting

Level

Accepting of

$1:$

1:

2:

\subsubsection{Level of teachers' TPACK after teaching}

After teaching, it was found that the four teacher participants showed knowledge of TPACK at Level 4 and Level 5 as they were actively willing to integrate the appropriate technologies for teaching mathematics. After their decision in using the appropriate technologies in their classroom teaching, importantly they performed a followed-up evaluation on the consequences in their classroom teaching. As displayed in Table 4, the teacher participants' excerpts after teaching are given which aligned accordingly with an indicator of their levels of TPACK.

Table 4. Teacher's excerpts and levels of TPACK after the intervention

Teac
hers
1 I found that the use of technology-based approach in geometry class
could turn learning atmosphere to be better obviously. The students were
interested in the class and that helped them in learning geometry. This
showed that the use of diverse and appropriate technologies supported
the students' effective learning.
2 I really liked Tinkercad program which was used in my class today

\section{Levels TPACK}

Level

Advancing of

5:

Level 
since it assisted my students to connect the concepts in geometry through the Application for learning geometry and GeoGebra program. This was useful in developing lesson plans which linked with the realistic situations. Also, it encouraged me to design new and different learning activities.

Apart from the use of Tinkercad program in connecting lesson plans with the real situations, I discovered that we could create key answers for the activities in lesson plan 5. The students could check their answers by drawing geometric shapes from front view, side view, and top view. Tinkercad program was beneficial for providing the students with various designs of learning activities.

I found that technology integration with the Application for learning geometry, GeoGebra program, and Tinkercad program with the suitable learning activities in the developed five lesson plans enabled the students to learn geometry effectively. I thought in that way because a diversity and suitability of technology usage that could create different learning activities based on teaching contents fulfilled the effectiveness in teaching and learning.
Exploring

Level

4:

Exploring

Level

5:

Advancing

\subsection{Students' Learning in Geometry}

A 30-item multiple choice geometric achievement pre-test and post-test were given to the students before and after learning geometry with technology-based approach lesson plans under the peer coaching process. The results of descriptive statistics (i.e., mean and standard deviation) are presented in Table 5.

Table 5. Students' pre-test and post-test mean scores

$\begin{array}{lllll}\text { Tests } & \text { Mean } & \text { Std. Deviation } & \text { Std. Error Mean } & \text { Percentage } \\ \text { Pre-test } & 13.75 & 2.75 & 0.49 & 45.83 \\ \text { Post-test } & 21.66 & 3.08 & 0.54 & 72.19\end{array}$

Table 5 indicates the results that post-test mean score $(\mathrm{M}=21.66, \mathrm{SD}=3.08)$ of the students was greater than that pre-test mean score $(M=13.75, S D=2.75)$. The results revealed that the students could improve their understanding in learning geometry. Following that, the results in Table 6 were used to determine the significant difference in pre-test and post-test mean scores of the students using paired-samples t test.

Table 6. Comparing pre-test and post-test mean scores

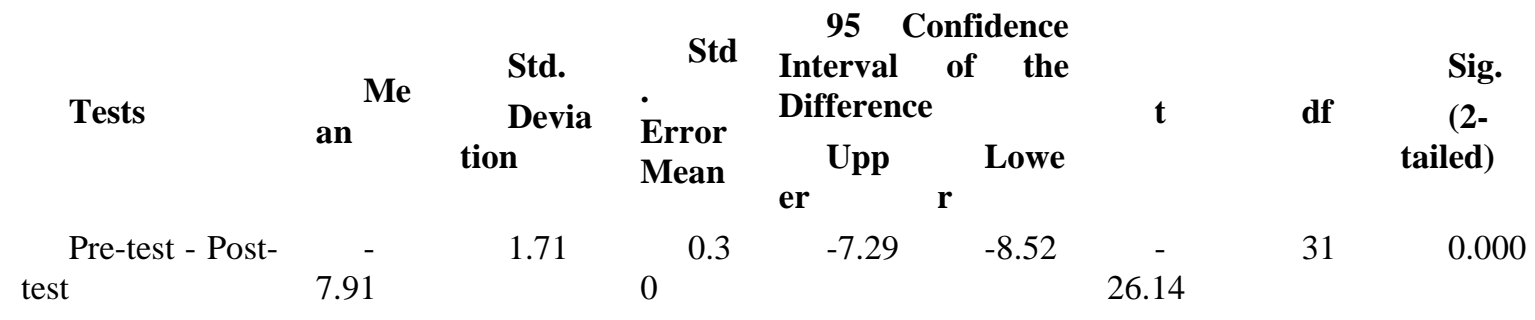

Table 6 showed that post-test mean score had statistically significant difference as compared to pre-test mean score, $\mathrm{t}(31)=-26.14, p<0.05$. The findings proved that the students could improve their understanding through the technology-based approach lesson plans under the peer coaching process.

One-sample t test was also used to compare the student participants' post-test mean score with a standard requirement of $60 \%$ (i.e., 18 scores). The results are reported in Table 7 below.

Table 7. Comparing post-test score with standard requirement of $60 \%$

\begin{tabular}{|c|c|c|c|c|c|c|c|}
\hline Test & Mean & $\mathbf{t}$ & df & $\begin{array}{l}\text { Sig. } \\
\text { (2- }\end{array}$ & $\begin{array}{c}\text { Mean } \\
\text { Difference }\end{array}$ & $\begin{array}{l}95 \text { Confidence } \\
\text { of the Difference }\end{array}$ & Interva \\
\hline & & & & tailed) & & Upper & Lower \\
\hline Post- & 21.66 & 6.73 & 31 & 0.000 & 3.66 & 4.77 & 2.55 \\
\hline
\end{tabular}


test

Note. Test value $=18(60 \%)$

Table 7 shows the post-test mean score among the students which obtained from the integrated technology-based approach lesson plans under the peer coaching process that was statistically significant different when comparing with the target standard of $60 \%$ (i.e., 18 scores), $\mathrm{t}(31)=6.73, p<0.05$. The student participants' achievement in post-test $(72.19 \%)$ was above $60 \%$ which interpreted that the students had an effective learning when they learned geometry with the integrated technology-based approach in the present research.

\section{Discussion}

The key research findings indicated the four teacher participants' average scores on TPACK before and after teaching geometry to seventh-grade students with the integrated technology-based approach under the peer coaching process was shifted from moderate level to high level. Therefore, the integrated technology-based approach brought a remarkable improvement to the teacher participants' TPACK. However, they had the lowest average score on technical skills which is the essential skill for technology integration in teaching. This postulates the fact that the teacher participants had low level of technological knowledge. In this study, the support of peer coaching with the operation in creating ideas of technology integration in lesson plan design, reflecting on the current teaching practices, and establishing new skills for technology integration in classroom teaching could develop the teacher participants' technological knowledge and TPACK. Moreover, the findings indicated that peer coaching could enhance the teacher participants' levels of TPACK. That is to say, before the process of peer coaching, they had TPACK at Level 1 and Level 2 which mean that they can just use the technology and recognize the alignment of the technology with mathematics content but cannot integrate the technology in teaching and learning of mathematics. After the process of peer coaching, on the other hand, the teacher participants showed TPACK at Level 4 and Level 5 which refer that they integrate teaching and learning of mathematics with an appropriate technology and evaluate its effectiveness in classroom teaching. The success in developing the teacher participants' TPACK resulted from the process of peer coaching which executed functions in encouraging a group community of teachers and improving knowledge in the community. This is in line with Shuman and Sherin's (2004) assertion which articulated that peer coaching creates a platform where teachers can interact with more capable teacher colleagues. When teachers with unique and different expertise involve in complex and authentic activities in one community, they are able to come up with feedback for developing and improving essential skills. This fact aligns with Zhang, Liu, and Wang's (2017) suggestion, noting that teachers in the process of peer coaching receiving feedback and support from each other can achieve an improvement of teaching skills and techniques. In addition to this, Jang (2010) claimed that peer coaching is effective in developing science teachers' TPACK as well.

The results of using peer coaching which improved the teacher participants' TPACK made teaching and learning of geometry more effective as reported in the students' significant greater post-test mean score in a comparison with pre-test mean score. Also, the students' post-test mean score was significantly greater than the target standard. Because of such findings, it can be explained that the students had benefits from learning geometry with the integrated technology-based approach under the peer coaching process. This is due to the teacher participants' development of TPACK which showed the positive impacts on establishing new skills for technology integration in their classroom teaching and designing learning activities with the use of the Application for learning geometry, GeoGebra program, and Tinkercad program. The aids from that software and application increased the students' understanding in learning geometry as they support operation with $2 \mathrm{D}$ and $3 \mathrm{D}$ functions. Besides than that, the software allows the students to learn and be exposed to learning of 2D and 3D geometric shapes. Consequently, the software users are able to construct and control solid geometric objects in 3D within a 2D interface. The advantages of using the software in learning geometry also include constructing, rotating, viewing 3D objects such as prism, pyramid, cylinder, and cone in different views. Links of multiple representations are crucial for assisting students' visualisation so that it is useful for students to explore, resolve, and connect concepts in geometry using the software and application. The results in geometric achievement in this study can assure that technology integration in teaching and learning enhanced the students' learning through visualization as supported by previous studies by Kösa and Karakuú (2010), Jackiw (2003), and Oldknow and Tetow (2008).

\section{Conclusion}

This study highlights the effectiveness of the integrated technology-based approach under the process of peer coaching in enhancing teachers' TPACK and students' understanding in learning geometry. It focuses on how using the process of peer coaching which supports and encourages teachers in generating ideas for improving classroom teaching can foster teachers' TPACK by integrating technology such as the Application for learning geometry, GeoGebra program and Tinkercad program in teaching geometry. The software and the application 
serve high-quality geometry instruction and provide examples that demonstrate how the appropriate use of technology can enhance students' understanding in learning geometry. Therefore, a teaching model integrating two compatible interventions of technology-based approach and peer coaching can offer an efficient way to facilitate the growth of teachers' TPACK and lead to the powerful lessons which visualization is emphasized while studying on geometry, especially 3D geometry. The integrated technology-based approach provides students to learn geometric concepts by exploring and visualizing geometric relationships easily. In this research, the researchers studied on a part of integrating two interventions of technology-based approach and peer coaching which showed the positive effects in enhancing teacher participants' TPACK and students' understanding in learning secondary geometry. It is suggested for further researchers to investigate the effects of technology-based approach and peer coaching for teaching and learning geometry in higher level or in other topics for an effective teaching and learning.

\section{Acknowledgement}

The researchers would like to thank Yala Rajabhat University for granting funding support in conducting this research.

\section{References}

[1] Adulyasas, L. (2017). Measuring and factors influencing mathematics teachers' technological pedagogical and content knowledge (TPACK) in three southernmost provinces, Thailand. In AIP Conference Proceeding of the Fourth International Conference on Research Implementation and Education of Mathematics and Science 2015, (pp. 050032-1-050032-7), Yogyakarta: Yogyakarta State University.

[2] Adulyasas, L., \& Yathikul, S. (2020). Transferring Van Hiele phase-based learning to the tablet application for enhancing secondary student's geometric thinking. Journal of Advanced Research in Dynamical and Control Systems, 12(4), 8-15. https://doi.org.10.5373/JARDCS/V12SP4/20201460

[3] Arslan, F. Y., \& Ilin, G. (2013). Effects of peer coaching for the classroom management skills of teachers. Journal of Theory and Practice in Education, 9(1), 43-59.

[4] Battista, M. T. (2002). Learning geometry in a dynamic computer environment. Teaching Children Mathematics, 8(6), 333-339.

[5] Clements, D. H. (2003). Teaching and learning geometry. In J. Kilpatrick, W. G. Martin, \& D. Schifter (Eds.), A Research Companion to Principles and Standards for School Mathematics, National Council of Teachers of Mathematics, Reston.

[6] Hohenwarter, M., \& Fuchs, K. (2004). Combination of dynamic geometry, algebra and calculus in the software system GeoGebra. Paper presented at the Computer Algebra Systems and Dynamic Geometry Systems in Mathematics Teaching Conference, Pecs, Hungary.

[7] Jackiw, N. (2003). Visualizing complex functions with the Geometer's Sketchpad. Paper presented at the Sixth International Conference on Technology in Mathematics Teaching. (pp. 291-299). Volos, Greece: University of Thessaly.

[8] Jang, S. (2010). Integrating the interactive whiteboard and peer coaching to develop the TPACK of secondary science teachers. Computers \& Education, 55(4, 1744-1751. https://doi.org/10.1016/j.compedu.2010.07.020

[9] Koehler, M. J., \& Mishra, P. (2009). What is technological pedagogical content knowledge? Contemporary Issues in Technology and Teacher Education, 9(1), 60-70.

[10] Kösa, T., \& Karakuú, F. (2010). Using dynamic geometry software Cabri 3D for teaching analytic geometry. Procedia Social and Behavioral Sciences, 2(2) 1385-1389. https://doi.org/10.1016/j.sbspro.2010.03.204

[11] Lu, H. L. (2010). Research on peer coaching in pre-service teacher education-A review of literature. Teaching and Teacher Education, 26(4), 748-753. https://doi.org/10.1016/j.tate.2009.10.015

[12] Mishra, P., \& Koehler, M. J. (2006). Technological pedagogical content knowledge: A framework for teacher knowledge. Teachers College Record, 108(6), 1017-1054.

[13] Mohapatra, B. N., Mohapatra, R. K., Joshi, J., \& Zagade, S. (2020). Easy performance-based learning of arduino and sensors through Tinkercad. International Journal of Open Information Technologies, 8(10), 73-76.

[14] Mullis, I. V., Martin, M. O., Foy, P., \& Hooper, M. (2015). TIMSS 2015 international results in mathematics, Lynch School of Education. Boston College: TIMSS \& PIRLS International Study Centre.

[15] National Council of Teachers of Mathematics. (2000). Principles and standards for school mathematics. Reston, VA: NCTM.

[16] Niess, M. L., Ronau, R. N., Shafer, K. G., Driskell, S. O., Harper, S. R., Johnston, C., Özgün-Koca, S. A., \& Kersaint, G. (2009). Mathematics teacher TPACK standards and development model. Contemporary Issues in Technology and Teacher Education (CITE Journal), 9(1), 4-24. 
[17] Norton, S., McRobbie, C. J., \& Cooper, T. J. (2000). Exploring secondary mathematics teachers' reasons for not using computers in their teaching. Journal of Research on Computing in Education, 33(1), 87-109. https://doi.org/10.1080/08886504.2000.10782302

[18] Oldknow, A., \& Tetlow, L. (2008). Using dynamic geometry software to encourage 3D visualization and modelling. The Electronic Journal of Mathematics and Technology, 2(1), 54-61.

[19] Pelgrum, W. J. (2001). Obstacles to the integration of ICT in education: Results from a worldwide educational assessment. Computers and Education, 37(2), 163-178. https://doi.org/10.1016/S03601315(01)00045-8

[20] Rice, G. (2012). Formative dialogues in teaching: Nonthreatening peer coaching. The Journal of Chiropratic Education, 26(1), 62-67. https://doi.org/10.7899/1042-5055-26.1.62

[21] Saha, R. A., Ayub, A. F. M., \& Tarmizi, R. A. (2010). The effects of GeoGebra on mathematics achievement: Enlightening coordinate geometry learning. Procedia Social and Behavioral Sciences, 8, 686-693. https://doi.org.10.1016/j.sbspro.2010.12.095

[22] Schmid, M., Brianza, E., \& Petko. D. (2020). Developing a short assessment instrument for technological pedagogical content knowledge (TPACK.xs) and comparing the factor structure of an integrative and a transformative model. Computers \& Education, 157, 1-12. https://doi.org/10.1016/j.compedu.2020.103967

[23] Serkoak, L. (1996). Working together in mathematics education. Alberta: Learning Resources Distributing Centre.

[24] Shamburg, C. (2004). Conditions that inhabit the integration of technology for urban early childhood teachers. Information Technology in Childhood Education Annual, 1, 227- 244.

[25] Shulman, L. S. (1986). Those who understand: knowledge growth in teaching. Educational Researcher, 15, 4-14.

[26] Shulman, L. S., \& Sherin, M. G. (2004). Fostering communities of teachers as learners: disciplinary $\begin{array}{lllll}\text { perspectives. Journal of } & \text { 135-140. }\end{array}$ https://doi.org/10.1080/0022027032000135049

[27] Sykes, G. (1996). Reform of and as professional development. Phi Delta Kappan, 77(7), 465-467.

[28]Zhang, S., Liu, Q., \& Wang, Q. (2017). A study of peer coaching in teachers' online professional learning communities. Universal Access in the Information Society, 16, 337-347. https://doi.org/10.1007/s10209-016-0461-4 